\title{
Resumption and Optionality in Arabic Definite Restrictive Relatives
}

\author{
Issa Abdel-razaq \\ Department of English Language and Literature \\ Irbid National University \\ Jordan \\ Tel: 962-2705-6682Ｅ-mail: issaabdelrazaq@ gmail.com
}

Received: August 18, 2020

doi:10.5296/ijl.v12i5.17544
Accepted: October 4, 2020

Published: October 19, 2020

URL: https://doi.org/10.5296/ijl.v12i5.17544

\begin{abstract}
The present study examines the claim that definite relative clauses in Modern Standard Arabic exhibit free variation between resumptive pronouns and gaps. The implication of such a claim presents a problem for minimalist syntax that does not tolerate true optionality. To solve this problem, the study argues that the original claim is incorrect and that despite similarities in the PF outputs, resumptive relatives are syntactically different from gapped relatives. While the latter is derived from a standard VSO structure, I propose, the former is derived from a topic-comment structure that already contains an RP. Thus, the fact that resumptive relatives contain resumptive pronouns has nothing to do with relativization, as is generally assumed. The study demonstrates that both resumptive relatives and gapped relatives are derived by movement in contexts that do not involve islands. As it turns out, resumption in relatives is used only as a last resort strategy to save structures in which movement is genuinely blocked, such as islands, from crash. Altogether the study concludes that the variation observed does not reflect true optionality, a finding that supports robust economy principles of minimalist syntax.
\end{abstract}

Keywords: Definite restrictive relatives, Modern Standard Arabic, Resumptive pronouns, Topic-comment sentences, Last resort

\section{Introduction}

The aim of the present study is twofold. First, it investigates the claim that relative clauses in Modern Standard Arabic (MSA, hereafter) exhibit free variation between gaps and 
resumptive pronouns in the relativization site that corresponds to the direct object (Shlonsky (1992) and Aoun, Benmamoun, and Choueiri (2010)). Consider the following examples.

1a. qabaltu

r-rajul-a

allaði ra?at-hu

Salma

met.1s

the-man-Acc

who saw.3fs-him

Salma

'I met the man that Salma saw.'

1b. qabaltu

r-rajul-a

allaði raPat $\varnothing$

Salma

met. $1 \mathrm{~s}$

the-man-Acc

who saw.3fs

Salma

'I met the man that Salma saw.'

In (1a), a resumptive pronoun (RP, hereafter) occupies the relativization site, whereas in (1b) the relativization site is occupied by a gap. Examples like (1a-b) appear to constitute empirical support for the claim made in Shlonsky (1992), and Aoun, Benmamoun and Choueiri (2010) that both resumption and movement are simultaneously possible in MSA definite relatives. This scenario gives rise to a conflict between empirical facts reflecting optionality and theoretical assumptions building the Minimalist Program (Chomsky 1995, 2000, 2001, 2007, 2008). From a minimalist perspective, to clarify, the claim that movement and resumption are both possible in relative structures in MSA is problematic. Any given numeration either contains the Edge Feature (EF) (Chomsky 2007, 2008) responsible for movement or it does not contain that feature. In the presence of the EF, movement is obligatory. If this feature is not present, on the other hand, movement is not possible. Theoretically, then, it is unlikely that a single numeration $n$ allows both presence and absence of the EF feature as this will result in two derivations, one with obligatory movement and another without movement, simultaneously. Such a scenario is not desirable, at least in minimalism. Indeed the Last Resort principle requires such superfluous steps in the derivation be minimized.

It is the task of the present study to settle the conflict presented by the MSA data between empirical claims for optionality and the theoretical economy drive of minimalist syntax. Upon closer examination of the MSA data, it will be suggested that the RP-gap variation does not reflect true optionality. Despite surface similarities between the two structures, I propose, resumptive relatives are syntactically (and semantically) different from gapped relatives. It will be demonstrated that whereas the input for relativization in resumptive relatives is a topic-comment construction that already contains a RP, the input for relative clauses with gaps is a regular VSO sentence. It is a mere coincidence that the PF outputs that result from the relativization processes in both cases are identical.

The second aim of the study is to argue that although resumptive relatives involve resumption, resumption in this instance does not have anything to do with relativization. That is to say, resumptive relatives are not derived by the resumption strategy per se. This argument contradicts the dominant view presented in Shlonsky (1992) and Aoun et al. (2010) whereby the default strategy in forming this type of relatives is the resumptive strategy. I will show that the resumption strategy is not the default strategy in deriving relative clauses in MSA. 


\section{Macrothink}

Instead, I will argue that the gap/movement strategy is the default strategy in forming relatives and treat the resumptive strategy as a last resort strategy that comes into play only when movement is not possible.

The sections of this paper are organized as follows. Section (2) presents types and properties of restrictive relative clauses in MSA along with the distribution of RPs and gaps. Section (3) provides a discussion of the data presented in section (2) and addresses the issue of whether MSA definite relatives truly display optionality between gaps and RPs. Section (4) puts forward a proposal that neatly solves the optionality problem. Section (5) concludes with the main findings of this study along with implications and recommendations for future research.

\section{Restrictive Relative Clauses in MSA: Properties and Distribution of RPs vs. Gaps}

This section introduces types of restrictive relative clauses in MSA and the properties generally associated with each type. This is then followed by a presentation of the distributional patterns of gaps and RPs in the direct object position inside the relative clause (Note 1).

There are two types of restrictive relative clauses in MSA: indefinite and definite. Indefinite relative clauses are distinguished by the following three uniformly consistent properties: indefiniteness of the noun phrase they modify, absence of a (overt) complementizer, and obligatory presence of a resumptive pronoun in the DO position. Consider the following examples.

2a. qabaltu

$$
\text { rajul-an }
$$

raPat-hu

Salma

met.1s

man-Acc

saw.3fs-him

Salma

'I met a man Salma saw.'

2b. *qabaltu

rajul-an

ra?at

Salma

met.1s

man-Acc

saw. $3 \mathrm{fs}$

Salma

2c. *qabaltu

al-rajul-a

raPat-hu

Salma

met.1s

the-man-Acc

saw.3fs-him

Salma

2d. *qabaltu rajul-an allaði

ra?at-hu

Salma

met.1s

man-Acc who

saw.3fs-him

Salma

3a. Jakara-ni

Talibu-un

saaład-tu-hu

thanked-me

student-Nom.sing

helped-1s-him

'A student I helped thanked me.'

3b. *Jakara-ni

Talibu-un

saạad-tu

thanked-me

student-Nom.sing

helped-1s

3c. *Jakara-ni

al-Talibu-u

saaSad-tu-hu 
thanked-me

3d. *Jakara-ni

thanked-me
the-student-Nom.sing

Talibu-un

student-Nom.sing helped-1s-him

allaði saạad-tu-hu

who helped-1s-him

These examples show that absence of any of the three properties results in ungrammaticality as seen in the ( $2 b-d)$ and (3b-d) examples. The only grammatical case is when these three properties are met altogether as in the sentences (2a) and (3a) above.

Likewise, definite relatives exhibit three properties: definiteness of the noun phrase they modify; obligatory presence of the relative clause complementizer; and RP-gap alternation in the DO position. Let us consider the first two properties illustrated by the examples below.

4a. qabaltu

met.1s r-rajul-a

the-man-Acc who

'I met the man that Salma saw.'

4b. *qabaltu

rajul-an

met.1s

a-man-Acc who

4c. *qabaltu

r-rajul-a

met.1s

the-man-Acc

5a. Jakara-ni

thanked-me
T-Talibu-u allaði

the-student-Nom who allaði ra?at(-hu)

saw.3fs(-him)

Salma

Salma

'The student that I helped thanked me.'

5b. * Jakara-ni

Talib-un

thanked-me a-student-Nom who

5c. *Jakara-ni

T-Talibu-u

thanked-me the-student-Nom allaði ra?at(-hu)

Salma

saw.3fs(-him)

Salma

ra?at(-hu)

Salma

saw.3fs(-him)

Salma

In the examples above, only definite noun phrases can be modified by definite relatives (4a) and (5a), respectively. Meanwhile, an indefinite noun phrase cannot be relativized in such contexts, hence the ungrammaticality in the (b) examples. Notice also that the relativized DP must always be followed by (one of the forms of) the complementizer allað $i$ 'that'. Absence of the relative complementizer induces ungrammaticality exemplified in the (c) cases.

The third property of definite relatives concerning the distribution of RPs and gaps in the DO position inside the clause is more interesting. That is, definite relatives display unexpected alternation between gaps and RPs in the relativization site as shown in the following sentences. 
6a. qabaltu

$$
\text { r-rajul-a }
$$

allaði

ra?at

Salma

met. $1 \mathrm{~s}$

the-man-Acc

who

saw.3fs

Salma

'I met the man that Salma saw.'

6b. qabaltu

$$
\text { r-rajul-a }
$$

allaði

ra?at-hu

Salma

met.1s

the-man-Acc

who

saw.3fs-him Salma

'I met the man that Salma saw.'

7a. Jakara-ni

T-Tullaab-u

allaðina

saaßadtu

thanked-me

the-students-Nom who.plms

helped.1s

'The students whom I helped thanked me.'
7b. Jakara-ni
T-Tullaabu-u
allaðina
saaSadtu-hum
thanked-me
the-students-Nom who.plms
helped.1s-them

'The students whom I helped thanked me.'

In (6) and (7), both gaps and RPs are perfectly acceptable in the DO position that corresponds to the relativized DPs $r$-rajul- $a$ 'the-man' and T-Tullaab- $u$ 'the-students', respectively. Notice too that the complementizer shows agreement in number and gender with the relativized DP. Indeed, MSA relative complementizer agree with the DP head of the relative clause in $\phi$-features, Definiteness and Case (Note 2).

The alternation between RPs and gaps disappears, however, when relativization takes place across islands. Consider the following examples (Aoun et al. (2010: 169)).

8a. ra?aytu 1-lawhata

allati taSrifiina

mann

ftara-ha

saw.I the-painting

that know.you(f)

who

bought-it

'I saw the painting that you know who bought it.'

8b. *ra?aytu 1-lawhata

allati taSrifiina

mann

Stara

saw.I the-painting

that know.you(f)

who

bought

9a. Sallaqtu 1-lawhata

allati saafarti

qabla an

?ajtari-ha

hung.I the-painting

that traveled.you(f)

before that

I.bought-it

'I hung the painting that you traveled before I bought it.'

9b. *Callaqtu 1-lawhata

allati saafarti

qabla an

a? ftari

hung.I the-painting that traveled.you(f)

before that

I.bought

In these examples, the relativized site that corresponds to the DO lies within an island, a wh-island in (8) and an adjunct island in (9), respectively. In such contexts, the dependency 
relationship between the relativization site and the relativized DP can be established only through resumption as in (8a) and (9a). Meanwhile, such dependency is broken when gaps occupy the relativization site in $(8 b)$ and $(9 b)$.

To recap, the data presented in this section sheds some light on the properties associated with indefinite and definite restrictive relatives. While indefinite relatives display a uniform set of properties, the situation is slightly different with definite relatives. For the latter, the facts reported show that there are two asymmetric patterns found in the distribution of RPs and gaps in the DO position. One pattern shows that RPs alternate with gaps in the DO position inside main clauses. The other pattern shows that RPs is obligatory when the relativized DP is separated from its corresponding internal argument position by an island. The fact that in non-island contexts definite relatives exhibit free variation between gaps and RPs is unexpected. Given that movement is not blocked, we expect to find gaps only and no RPs. This state of affairs calls for an explanation. The next section discusses this issue in detail.

\section{Discussion and Review}

The previous section presented types and properties of restrictive relatives in MSA. Amongst the properties reported is one that deserves careful investigation, namely the distribution of gaps and RPs in the DO position of definite relatives. As has been noted, in those contexts both gaps and RPs may occupy this position. This kind of alternation poses several problems that we discuss in this section.

From a theoretical perspective, the RP/gap alternation presents a conceptual challenge for minimalist syntax that seeks to reduce the linguistic apparatus to the minimum. Within this framework, movement is necessarily motivated, an element will only move if the numeration includes an Edge Feature (Chomsky 2007), and is obliged to move if such a feature is present. In the absence of such a feature, movement is categorically disallowed. Admitting such alternation amounts to allowing relative structures to be formed by either movement (in the case of gaps) or base-generation (in the case of RPs). In other words, relative clauses may be formed by movement which in this case means that the numeration must contain the movement feature or by resumption which in this case means that the numeration includes a resumptive pronoun. Minimalist syntax, however, does not tolerate such unmotivated alternation in the course of derivation as apparently suggested by the MSA optionality facts.

The other related problem is empirical and concerns the claim that resumption is the default strategy for relative clause formation in MSA (Aoun et al. 2010). Given that nothing bans movement from the direct DO inside relative clauses, where no islands involved, the presence of RPs does not necessarily mean that the resumptive strategy is not used for relativization, nor does it signal true optionality between movement and resumption. Such a claim would necessarily require careful investigation and examination of other structures involving RPs, especially in a language like MSA that uses resumption productively (see Farghal (1986); Fassi Fehri (1993); Mohammad (2000); and Ryding (2005)).

The problems associated with optionality as outlined here have received little attention in the literature on Arabic relatives. An early work of Shlonsky (1992) observes optionality in MSA 
relatives and provides the following paradigm from MSA showing the same alternation facts reported earlier.

10a. Pal-rajul-u

the-man-Nom

'The man that I saw.'

10b. Pal-mar?at-u

the-woman-Nom

'The woman that I saw.'

10c. Pal-Pawlaad-u

the-boys-Nom

'The boys that I saw.'

10d. Pal-nisa?-u

the-women-Nom

'The women that I saw.'

10e. Pal-walaad-aani

the-two.boys-Nom
raPaytu(-hu)

that.MS

I.saw(-him)

raPaytu(-ha)

I.saw(-her)

that.FS

allaðiina

raPaytu(-hum)

that.MPL

I.saw(-them)

raPaytu(-hunna)

I.saw(-them.F)
raPaytu(-huma)

that.M.Nom-DUAL
I.saw(-them.DUAL)

'The two boys that I saw.'

10f. raPaytu Pal-Pawlaad-ayni

I.saw the-two.boys-Acc allað-ayni

that.M.Acc-DUAL
Sadaa

came.back

'I saw the two boys that came back.'

For Shlonsky, examples like the above indicate that definite relatives display optionality. In fact, Shlonsky goes further and argues that optionality in MSA relatives is not between RPs and gaps, but between a RP and a pro. Shlonsky manipulates a distinction between the A/A' statuses of the relative Comp to explain (lack of) movement. The fact that the MSA relative complementizer bears $\phi$-features leads Shlonsky to assume that it identifies its Spec, that is SpecCP, as an A-Spec. Movement from the DO position to Spec, CP induces a violation of the Specified Subject Condition (Chomsky 1973); only the subject closest to C can move. Since movement is blocked, the object position is occupied by a RP as a last resort strategy. On the other hand, when $\mathrm{C}$ identifies its Spec as an $\mathrm{A}^{\prime}$-position, movement becomes syntactically available and no RP is needed. Occurrence of pro is legitimate in the sense that it can be recovered from the features of the relative complementizer. Hence, optionality in such contexts indicates a choice between a RP and phonetically null version of it. 
In spite of its insightful methodology, Shlonsky's analysis deals with optionality as a phenomenon characteristic of MSA relatives without questioning it the way this study does. His analysis is not without problems. For instance, Shlonsky's analysis overlooks the fact that structures in which pronouns appear cannot receive the same treatment as structures in which the pronoun is absent, at least semantically, as will be demonstrated in the following section. Not to mention the fact that, syntactically, the claim that the Arabic relative complementizer identifies its Spec as an A-position requires a superfluous process that re-assigns it an $\mathrm{A}^{\prime}$-status at LF to ensure construction and interpretation of the appropriate relations.

The other work on optionality that can be mentioned in this context is that of Aoun, Benmamoun and Choueiri (2010) who claim that the resumptive strategy is the default strategy for forming definite relatives like (11a). Nevertheless, Aoun et al. also present data from MSA like (11b) showing that gaps are possible in the DO position.
11a. PaSrifu l-muma $\theta$ ilat-a
allati sa-yuqabilu(-ha)
Saami
I.know the-actress-Acc
who Fut-meet.3MS(-her)
Saami

'I know the actress that Sami will meet.'
11b. ra?aytu 1-lawhat-a
allati quita
Pinna-ka
sa-taftari-(ha)
saw.I the-painting-Acc
that said.2MS
that-you(ms)
Fut.buy.2MS(-it)

'I saw the painting that you said you will buy.'

The facts built on examples like (11) lead Aoun et al. to contend that there is alternation between RPs and gaps in MSA definite relatives but they offer no explanation as to why or rather how this alternation takes place.

The present study considers optionality a problematic issue that, if true, casts doubts on the compatibility of core minimalist assumptions and one that must be accounted for. In this respect, this study settles the conflict between MSA empirical facts and minimalism by offering a simple yet convincing solution. It suggests that the optionality found in MSA definite relatives is not true optionality. Even though their surface structures are almost the same, relative clauses with RPs are syntactically (and semantically) different from relative clauses with gaps. More precisely, I propose that relative clauses with gaps are classic cases of relativization out of a standard VSO sentence. These are derived by movement of the relativized noun phrase from the DO position into $\mathrm{Spec}, \mathrm{CP}$, leaving behind a silent copy in the extraction site. As for relative clauses with RPs, I take these to be cases of relativization out of another common type of sentence, namely topic-comment sentences derived by movement of the topic noun phrase immediately below the $\mathrm{CP}$ into Spec, $\mathrm{CP}$. This noun phrase is related to a RP that exists in the structure before relativization takes place. Before spelling out the whole proposal, it is worth presenting types of sentence in MSA to highlight the main properties associated with topic-comment sentences that will be crucial for understanding the overall analysis. 


\section{Solution}

\subsection{Sentence Types in MSA}

There are two types of sentence in MSA traditionally known as verbal sentences and nominal sentences (Fassi-Fehri (1993); Shorafat (1999); Benmamoun (2000); Mohammad (2000); Ouhalla and Shlonsky (2002); Ryding (2005); Al-Horais (2006); Soltan (2007); Aoun et al. (2010); and Abdel razaq (2012) and (2017)). Verbal sentences are those sentences that contain and begin with a verb; the basic word order is Verb-Subject-(Object) shown in (12) below.

$$
\begin{array}{ll}
\text { 12a. ja?a } & \text { 1-muhandis-u } \\
\text { came.3ms } & \text { the-engineer-Nom }
\end{array}
$$

'The engineer came.'
12b. zara
1-wazeer-u
al-markaz-a
1-Өaqafeyy-a
visited. $3 \mathrm{~ms}$
the-minister
the-center-Acc
the-cultural-Acc

'The minister visited the cultural center.'

Nominal sentences, on the other hand, are those sentences that begin with a noun phrase. These are also called topic-comment sentences simply because they contain a topic and a comment that presents the event predicated of the topic. Topic-comment sentences can be further classified into two types. The first type, call it simple topic-comment sentences, contains a subject DP (the topic) and a predicate (the comment) but does not contain a verb as in (13a-c) below.
13a. al- moSallim-u
mulhim-un
the-teacher-Nom
inspirer.Nom

'The teacher is an inspirer.'

13b. al-a?wlaad-u

masroor-uun

the-boys-Nom

happy-Nom

'The boys are happy.'
13c. al-a?wlaad-u
fi-l-madarasat-i
the-boys-Nom
in-the-school.Gen

'The boys are at school.'

Sentences (13a-c) represent the basic subject-predicate sentences in Arabic with the schematic structure [DP XP]. In this type of sentence, the XP predicate can be a noun phrase (13a), an adjective phrase (13b), or a prepositional phrase (13c). 


\section{Al Macrothink}

International Journal of Linguistics

ISSN 1948-5425 2020, Vol. 12, No. 5

The second type of topic-comment sentences contains a fronted DP (topic) followed by a complete predicational compound (comment) consisting of a verb, a subject and a resumptive element. Consider the following examples.
14a. al-a?wlaad-u
raPaytu-hum
fi-1-madarsa
the-boys-Nom
saw.1s-3mpl
in-the-school

'The boys, I saw them in the school.'

14b. al-kitaab-u

Parsal-na-hu

maSa

Ahmad

the-book-Nom

sent-1pl-3ms

with

Ahmad

'The book, we sent it with Ahmad.'

The sentences in (14) above represent the complex type of nominal sentences. The topics $a l-a$ ? wlaad- $u$ 'the boys' and al-kitaab- $u$ 'the book' are followed by full predicational units combining the verb with the subject (agreement inflection) and the resumptive pronouns -hum (3MPL) and - $h u$ (3MS) corresponding to the topic DP.

Of the two types of topic-comment sentences, the one that concerns us here is the second type, i.e., the complex type. Following Abdel razaq (2012, 2017), I take topic-comment sentences to be the outcome of base-generation processes whereby both the preverbal DP, namely the topic, and the RP are merged in their respective positions in the surface structure. This necessarily means that the RP and the DP are included in the initial numeration that feeds syntactic operations. A skeletal structure for topic-comment sentences of the type we are dealing with here can roughly be represented as follows (moved constituents are inserted inside two angles $<>$ ).

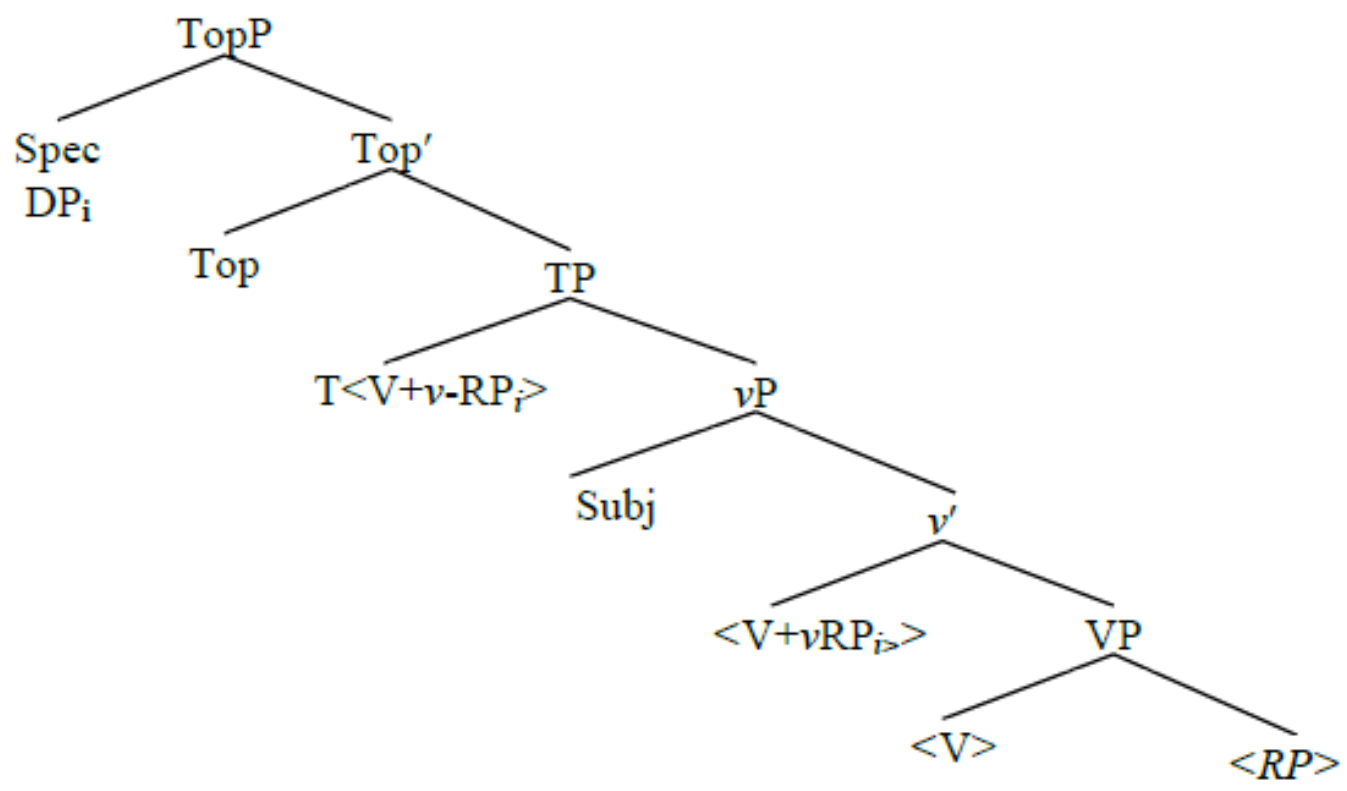


In this structure, the position that the DP occupies is the position designated for topics (see Rizzi (1997) and Shorafat (1999)), namely the specifier position of a Topic Phrase. Likewise, the RP is base-generated in the DO position inside the clause and is co-indexed with the topic DP (Note 3). It is noteworthy at this juncture that since object RPs are weak, unlike subject pronouns, they must be morphologically supported, hence, their attachment to the verb. The verb-RP complex then undergoes movement through transitive little $v$ to $\mathrm{T}$ in order to check its affixal tense feature (Benmamoun (2000) and Soltan (2007)). Meanwhile, the subject remains in its canonical specifier position of $v \mathrm{P}$ as the structure above shows. The outcome of these operations gives the linear structure DP-V+RP-S, namely the structure of topic-comment sentences. With this background, I turn next to putting together the pieces of the analysis proposed for explaining optionality facts observed in definite relative clauses in MSA.

\subsection{Proposal: Different Relativization Inputs-Similar PF Outputs}

The previous section presented the two types of sentence in MSA: the standard VSO sentence and the nominal topic-comment sentence. The latter has been further subdivided into simple predicational sentences containing a subject and a predicate (NP, AdjP or PP) and complex predicational sentences that contain the topic and a predicational compound containing a verb, a subject and a RP object. In this section, I argue against the view that relative clauses exhibit free variation between gaps and RPs (Shlonsky 1992) and (Aoun et al. 2010). It will be demonstrated that the alternation between RPs and gaps in relative clauses in MSA does not necessarily signal true optionality. It simply indicates that gapped relatives and resumptive relatives are derived from different types of sentence in spite of similarities in the PF outputs. The overall hypothesis states that all definite relatives that do not involve islands are derived by the movement-gap strategy and that the resumption strategy is a last resort strategy operating in structures that genuinely block movement. Under this hypothesis, relative clauses with gaps result from a standard movement derivation the input for which is a VSO sentence. As for the resumptive relatives, these are derived from complex topic-comment sentences that differ syntactically and semantically from VSO sentences. Hence, resumptive relatives differ in their syntax and semantics from gapped relatives. The next two subsections demonstrate how the two types of relative are different in spite of PF similarities that have led many to wrongly assume optionality as a feature of definite relatives,.

\subsection{Relativization Out of VSO Sentences}

This section demonstrates that relative clauses with gaps result from a standard movement derivation whose input is a VSO sentence, the unmarked order in MSA. The DP to be relativized undergoes movement to the Spec position of the clause that it heads. Following Vergnaud (1974), Kayne (1994), Bianchi (2000) and Aoun and Li (2003), I adopt the head raising analysis that involves a complementation structure and a head movement process illustrated in the following configuration (Note 4). 
(16)

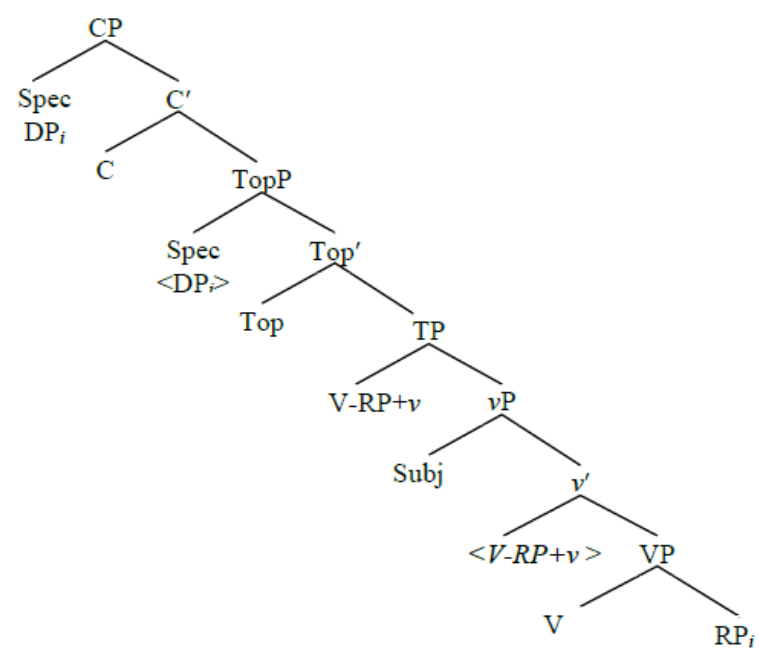

Under this analysis, the full relative construction projects as a DP (Note 5). The relative CP forms the complement of the external D occupied by the definite determiner the. The head of the relative clause rises from the DO position to the specifier position of the relative clause. The $\mathrm{C}$ head of the relative clause is occupied by (one of the forms of) the lexical complementizer allað $i$ that bears $\phi$-features and Case (see section 2). In addition, since this complementizer occurs only in definite relative clauses, I assume that it also bears a [Def] initeness feature. The relevant point in the derivation that concerns us here is where $\mathrm{C}$ merges with TP. Following Chomsky $(2007,2008)$, I take C to be an active probe that searches for an active goal with matching features within its c-command domain. It finds the DO at the edge of $v \mathrm{P}$, Spec, $v \mathrm{P}$, that bears the matching features. The operation Agree takes care of the evaluation of the uninterpretable features. The final step in the derivation before spell out is motivated by the assumption that $\mathrm{CP}$ is a phase and has an Edge Feature that requires movement of the agreeing DP to its specifier position. Since nothing in this structure blocks movement and since $\mathrm{C}$ has the feature that triggers movement, movement of the DP to Spec, $\mathrm{CP}$ is obligatory (Note 6). After movement, the DP leaves behind a copy that receives a null spell-out at the PF interface. The resulting structure is a definite relative clause with a gap in the DO position.

The analysis just outlined accounts for definite relatives that involve a gap in the relativization site. Despite the fact that the derivation of this type of relative clause is straightforward it is crucial for understanding why definite relatives display what might seem to be optionality between gaps and RPs. The next step in our analysis is to provide a derivation for relative clauses with RPs that is not based on the same numeration used for definite relative that with gaps.

\subsection{Relativization Out of Topic-Comment/Nominal Sentences}

In the previous section, I have shown that MSA relative clauses with gaps are derived by movement of the DO from its base position to Spec, $\mathrm{CP}$ and that the structure feeding this process is a standard VSO structure. In this section, I demonstrate that relative clauses with 


\section{Macrothink}

International Journal of Linguistics

ISSN 1948-5425

2020, Vol. 12, No. 5

RPs are also derived by movement, all be it the input for relativization is a topic-comment sentence that already contains a RP co-indexed with the topic DP. This is a common type of sentence in all Arabic dialects including MSA. Hence, forming relative clauses out of topic-comment sentences is equally common. Examples of topic-comment sentences are repeated below for convenience.

17a. al-a?wlaad-u

the-boys-Nom
raPaytu-hum

saw.1s-3mpl

\section{fi-1-madarsat-i}

in-the-school-Gen

'The boys, I saw them in the school.'

17b. al-kitaab-u

$$
\text { Parsal-na-hu }
$$

maSa

Ahmad-i

the-book-Nom

$$
\text { sent-1pl-3ms }
$$

with

Ahmad-Gen

'The book, we sent it with Ahmad.'

In section (4.1) above, topic-comment sentences like (17) have been analyzed structurally as Topic Phrases in which both the preverbal DP and the RP are base-generated in their PF positions, i.e., Spec TopP and the DO position complement of $\mathrm{V}$, respectively (see the structure in section 4.1). When relativization operates on this structure, it targets the DP in the Spec position of TopP to head the relative clause. Under the hypothesis advocated earlier, the movement strategy is the default strategy in forming relative clauses in MSA. Since nothing bans movement, the DP in Spec, TopP undergoes movement Spec, CP. Relativization in this instance is the same as VSO sentences. The $\mathrm{C}$ head that the relative complementizer acts as a probe looking for a goal with matching features in order to value its uninterpretable features, namely $\Phi$-features, definiteness and Case features. The first candidate in the domain of $\mathrm{C}$ is the DP in Spec, TopP. Once Agree between C and the DP takes place, the latter is attracted to Spec, $\mathrm{CP}$ as a result of the $\mathrm{EF}$ of $\mathrm{C}$. Now consider the skeletal tree structure roughly diagrammed below (Note 7).

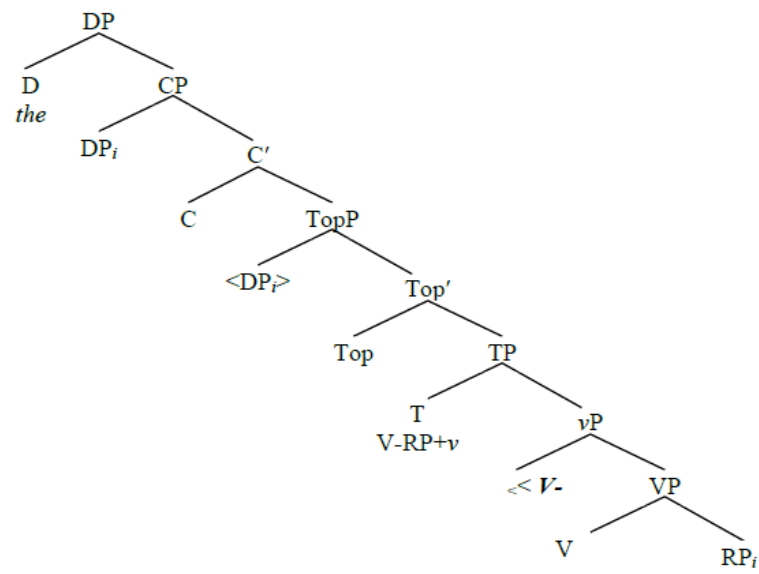

The suggestion that relativization operates on a topic-comment sentence straightforwardly accounts for the presence of a RP inside the clause and that this RP is related to the fronted 
DP prior to relativization. Under the current analysis, resumption has nothing to do with relativization. It is rather a characteristic of the structure that feeds relativization. Therefore, the resumption strategy is not what it is assumed to be. It is not a strategy per se randomly employed for relative clause formation. This goes against the dominant view (Aoun (1996), Choueiri (2002); Aoun et al. (2003); Aoun et al. (2010) and references therein) that resumption is the default strategy for forming relatives. More importantly, the analysis here overcomes the problematic stipulation that RPs freely alternate with gaps simply because of similarities in the PF outputs.

Thus far the proposed analysis supports the view that the movement-gap strategy is the default strategy in the formation of definite relatives. Accordingly, relatives with RPs require a treatment different from relatives with gaps despite the fact that both are derived by movement. Whereas relatives with gaps are derived from a standard VSO structures, relatives with RPs are derived from a topic-comment structure that already contains a RP. Broadly speaking, the analysis has the advantage of explaining that the acclaimed free alternation between gaps and RPs is not in fact a true alternation that would otherwise be problematic. Simultaneously, it provides further support for minimalist economy-driven principles that prefer movement over resumption given that Move is less costly than Bind (Shlonsky (2002); Aoun et al. (2003); and Aoun et al. (2010)).

Before closing this section, there remains one issue to resolve. So far, we have been dealing with cases where movement of the relativized DP to Spec, CP is possible, i.e., from the DO position in gapped relatives and from Spec, TopP position in resumptive relatives. There are contexts, however, in which such movement cannot be launched. The question that one might ask at this point is whether a relativization dependency can still be legitimately established. The analysis developed here supports the view that resumption here can still be used as a last resort strategy to save derivations that genuinely block movement from crash. To substantiate such a view, two arguments can be appealed to. The first argument comes from relative clauses that involve islands. The relevant examples are repeated below.

18a. ra?aytu 1-lawhata

saw.I the-painting that mann Jtara-ha bought-it

'I saw the painting that you know who bought it.'

18b.*ra?aytu 1-lawhata

saw.I the-painting that

19a. Sallaqtu 1-lawhata

hung.I the-painting that

$$
\begin{array}{ll}
\text { allati taSrifiina } & \text { mann Jtara } \\
\text { know.you(f) } & \text { who bought } \\
\text { allati saafarti } & \text { qabla an }
\end{array}
$$$$
\text { traveled.you(f) }
$$$$
\text { before that }
$$

'I hung the painting that you traveled before I bought it.'

19b. *Callaqtu 1-lawhata

hung.I the-painting that allati saafarti

traveled.you(f) qabla an

before that a? $\int \operatorname{tari}$

I.bought 
In such contexts, the dependency between the relativized DP and the relativization site cannot be established by movement due to the fact that islands are barriers to movement. Movement in this instance violates locality conditions, such as the Phase Impenetrability Condition (PIC) (Chomsky 2001), in which case the derivation does not converge, as indicated by the ungrammaticality of the (b) examples above. However, such a crash can be avoided if the grammar allows resumption to operate, i.e., as a last resort maneuver. Indeed, resumption is a tool commonly used in MSA (Note 8). In island context, RPs is included in the numeration at the initial stage of relative clause formation. Both the relativized DP and the RP are, then, merged in their respective PF positions while the operation Agree takes care of the valuing of the uninterpretable features. Because resumption is immune to islands, the long-distance dependency between the relativized DP in matrix Spec, CP and the RP in the relativized position inside the clause survives the crash, hence the grammaticality of (18a) and (19a).

The second argument that supports the current analysis comes from indefinite relative clauses which we have looked at earlier. Indefinite relatives display a contrast between RPs and gaps. To illustrate, consider the following examples.

$\begin{array}{cccc}\text { 20a. qabaltu } & \text { r-rajul-an } & \text { raPat*(-hu) } & \text { Salma } \\ \text { met.1s } & \text { the-man-Acc } & \text { saw.3fs } & \text { Salma }\end{array}$

'I met the man that Salma saw.'
20b. Jakara-ni
Talib-un
saaßad-tu*(-hu)
thanked.3ms-me student-Nom
helped-I-him

'A student I helped thanked me.

These sentences show that indefinite relatives cannot be formed by the movement-gap strategy. Meanwhile, indefinite relatives with RPs are perfectly acceptable. This is an unexpected situation since, theoretically, movement is possible from the DO position. What one predicts here is for the movement-gap strategy to be the only strategy available for forming relatives. This prediction is not borne out, however, and the contrast between RPs and gaps must be explained. Recall that under the present analysis, definite relatives that do not involve islands are derived by movement. Definite relatives with gaps are derived from VSO structures while those with RPs are derived from topic-comment sentences. In island contexts -and other contexts that block movement- resumption is used as a last resort strategy. If we extend this analysis to indefinite relatives, the fact that they involve RPs is taken to indicate that relativization operates on a topic-comment sentence. There is empirical evidence, though, that this derivation cannot be extended to indefinite relatives. MSA bans the occurrence of indefinite DPs in the initial position. Only definite DPs may occupy this position. The following examples illustrate the contrast.

$\begin{array}{ccc}\text { 21a. ar-rajul-u } & \text { raPat-hu } & \text { Salma } \\ \text { the-man-Nom } & \text { saw.3fs-him } & \text { Salma }\end{array}$

'The man, Salma saw him.' 
21b. *rajul-un

a-man-Nom ra?at-hu

Salma

Salma

The contrast above shows that only definite DPs can be topics (21a), indefinite DPs cannot (21b). This means that the input for indefinite relatives cannot be a topic-comment sentence. The question remains, however, as to how to account for the occurrence of RPs in indefinite relatives? It must be the case that since movement in indefinite relatives is not possible, given the ban on the occurrence of indefinite DPs in the initial position, resumption operates as a last resort strategy. In other words, the only possible alternative for the derivation to converge is to use the resumption strategy in order to establish a well-formed dependency between the relativized DP and its corresponding relativization site. Thus, indefinite relatives provide extra evidence for the case presented here that resumption is used as a last resort strategy in structures that genuinely block movement.

\section{Conclusion}

In this paper, I have examined the claim that definite restrictive relatives in MSA display free alternation between RPs and gaps in the DO position (Shlonsky (1992) and Aoun et al. (2010)). I have shown that such a claim presents a problem for the minimalist approach to syntax in that such alternation boils down to admitting optionality between two numerations that yield the same PF output, an undesirable scenario for minimalism. Upon closer examination of the MSA data, the study has revealed that the PF output of relative clauses with RPs and the one with gaps does not necessarily imply free alternation. Pursuing this view, I have demonstrated that relative clauses with RPs differ syntactically from relative clauses with gaps and must not therefore be treated as an optional construction for producing definite relatives.

The proposal put forward treats relative structures with gaps as cases of relativization from a standard VSO sentence that represents the unmarked word order in MSA. Relativization in such structures involves movement of the DP object to Spec, CP in the sense of Vergnaud (1974). Movement of this DP is triggered by the Edge Feature (Chomsky 2007) that the C head of the relative clause has. As for relative clauses with RPs, these have been treated as cases of relativization out of a topic-comment sentence that involves a DP topic related to a RP within the comment part, both of which are included in the initial numeration. I have demonstrated that relativization out of topic-comment sentences also involves movement, all be it movement is launched from Spec, TopP, the position of the topic DP, to Spec, CP.

The study concluded that all definite relative clauses that do not involve islands are derived by movement despite the presence of RPs in resumptive relatives. Where movement is genuinely blocked as in island contexts and indefinite relatives, resumption is used a saving device for structures that otherwise would be ungrammatical. Overall, the analysis advanced here fits well within principal guidelines of economy-based approaches to syntax, particularly Minimalism. It provides uniform treatment for definite relatives in the sense that both resumptive relatives and gapped relatives are derived by movement even though the launching site for each type of relative is not the same. It remains to be seen whether this 
analysis can be extended to other languages that display a similar phenomenon; an issue left for future research.

\section{References}

Abdelkader, F. F. (1993). Issues in the Structure of Arabic Clauses and Words. Dordrecht: Kluwer.

Bernadette, P. (1993). The position of subjects in Modern Standard Arabic. In M. Eid, \& C. Holes (Eds.), Perspectives on Arabic linguistics $V$ (pp. 231-260). Amsterdam: John Benjamins.

Clive, H. (2004). Modern Arabic: Structures, Functions, and Varieties. Washington, D.C.: Georgetown University Press.

Elabbas, B. (2000). The feature structure of functional categories: a comparative study of arabic dialects. Oxford: Oxford University Press.

Farghal, M. (1986). The Syntax of Wh-questions and Related Matters in Arabic. Doctoral dissertation. Indiana University, Bloomington.

Islam, Al.-M. (2010). Direct Object Relative Clauses in Jordanian Arabic: A Minimalist Approach. International Journal of Academic Research, 2(3), 226-237.

Issa, A. R. (2012). Who is what and what is who: the morphosyntax of Arabic WH. Cambridge Scholars Publishing. UK.

Issa, A. R. (2017). The Highest Subject Restriction and the Pro-Drop Parameter in Arabic. International Journal on Studies in English Language and Literature (IJSELL), 5(10), 96-106. https://doi.org/10.20431/2347-3134.0510012

Issa, A. R., \& Mahameed, M. (2017). The Morphosyntax of Negative Pronouns Constructions in Jordanian Arabic. Advances in Language and Literary Studies, 8(3), 133-154. https://doi.org/10.7575/aiac.alls.v.8n.3p.133

Jamal, O. (2004). Semitic Relatives. Linguistic Inquiry, 35, 288-300. https://doi.org/10.1162/002438904323019084

Joseph, A. (1996). Resumption and Last Resort. DELTA, 16(special issue), 13-43. https://doi.org/10.1590/S0102-44502000000300001

Joseph, A., \& Li, Y.-H. A. (2003). Essays on the representational and derivational nature of grammar: the diversity of wh-constructions. Cambridge, Mass.: MIT Press.

Joseph, A., Benmamoun, E., \& Choueiri, L. (2010). The Syntax of Arabic. Cambridge University Press.

Joseph, A., Choueiri, L., \& Hornstein, N. (2001). Resumption, Movement, and Derivational Economy. Linguistic Inquiry, 32, 371-403. https://doi.org/10.1162/002438901750372504 


\section{Macrothink}

International Journal of Linguistics

ISSN 1948-5425

2020, Vol. 12, No. 5

Lina, C. (2002). Re-visiting relatives: Issues in the syntax of resumptive restrictive relatives. Doctoral dissertation, University of Southern California, Los Angeles.

Luigi, R. (1997). The Fine Structure of the Left Periphery. In L. Haegeman (Ed.), Elements of Grammar (pp. 281-337). Dordrecht: Kluwer. https://doi.org/10.1007/978-94-011-5420-8_7

Mohammad, M. (2000). Word Order, Agreement and Pronominalization in Standard and Palestinian Arabic. Amsterdam: John Benjamins. https://doi.org/10.1075/cilt.181

Mohammad, S. (1999). Topics in Arabic: A minimalist Approach. Al-arabiyyah, 32, 1-21.

Nasser, Al.-H. (2006). Arabic verbless sentences: is there a null VP?. Pragmalinguistica, 14, 101-116. https://doi.org/10.25267/Pragmalinguistica.2006.i14.07

Noam, C. (1995). The minimalist program. Cambridge, Mass.: MIT Press.

Noam, C. (2000). Minimalist inquiries: the framework. In H. Lasnik, R. Martin, D. Michaels, \& J. Uriagereka (Eds.), Step by step. Essays on minimalist syntax in honor (pp. 89-155). Cambridge, MA: MIT Press.

Noam, C. (2001). Derivation by phase. In M. Kenstowicz (Ed.), Ken Hale: a life in language (pp. 1-52). Cambridge, MA: MIT Press.

Noam, C. (2007). Approaching UG from below. In U. Sauerland, \& H.-M. Gärtner (Eds.), Interfaces + recursion = language? (pp. 1-29). New York: Mouton de Gruyter.

Noam, C. (2008). On phases. In J.-R. Vergnaud, R. Freidin, C. P. Otero, \& M. L. Zubizarreta (Eds.), Foundational issues in linguistic theory: essays in honor (pp. 133-166). Cambridge: MIT Press.

Noam, C. (2013). Problems of projection. Lingua, 130, 33-49. https://doi.org/10.1016/j.lingua.2012.12.003

Richards, K. (1994). The antisymmetry of syntax. Cambridge, Mass.: MIT Press.

Ryding, K. C. (2005). A Reference Grammar of Modern Standard Arabic. Cambridge University Press. https://doi.org/10.1017/CBO9780511486975

Shlonsky, Ur. (1992). RPs as last resort. Linguistic Inquiry, 23(3), 443-468.

Shlonsky, Ur., \& Ouhalla, J. (2002). Themes in Arabic and Hebrew Syntax. Dordrecht: Kluwer.

Usama, S. (2007). On formal feature licensing in minimalism: Aspects of standard Arabic morphosyntax. Ph.D. Dissertation, University of Maryland, College Park Press.

Valentina, B. (2000a). The raising analysis of relative clauses: A reply to Borsley. Linguistics Inquiry, 31, 123-140. https://doi.org/10.1162/002438900554316

Valentina, B. (2000b). Some issues in the syntax of relative determiners. In A. Artemis, L. Paul, M. Andre, \& W. Chris (Eds.), The syntax of relative clauses (pp. 53-82). Amsterdam: John Benjamins. https://doi.org/10.1075/la.32.02bia 


\section{Macrothink}

Vergnaud, J. R. (1974). French Relative Clauses. Doctoral dissertation, Massachusetts Institute of Technology, Cambridge, Massachusetts.

\section{Notes}

Note 1. The study is concerned with the distribution of RPs and gaps in the direct object position only. The distribution of gaps and RPs in the subject position is equally interesting and requires an independent study. Detailed discussion on this topic can be found in Shlonsky (2002), and Abdel razaq (2017).

Note 2. See Shlonsky $(1992,2002)$ and Ouhalla (2004).

Note 3. See Abdel razaq $(2012,2017)$ for full discussion and references cited therein.

Note 4. See Aoun (1996), Ouhalla (2004) and Al-momani (2010) for a different analysis.

Note 5. See Ouhalla (2004) for a similar treatment.

Note 6. Movement of the head in this instance involves movement of a DP with an empty D. The external D licenses the internal empty D of the raised DP in Spec,CP while the DP provides the NP necessary for the interpretation of the external D. The process responsible for the licensing and interpretation is an incorporation process thanks to adjacency between the two Ds.

Note 7. Recall that the DP that moves has an empty D. The empty D gets licensed by the external D. Meanwhile, the DP provides the NP necessary for the interpretation of the external D. Since they are adjacent, the licensing of the empty D and the interpretation of the external D are taken care of by an incorporation process along the line of Bianchi (2000).

Note 8. See Aoun (1996); Aoun, Choueiri and Hornstein (2001); Aoun et al. (2003); and Aoun et al. (2010) for discussion on resumption in Arabic.

\section{Copyrights}

Copyright for this article is retained by the author(s), with first publication rights granted to the journal.

This is an open-access article distributed under the terms and conditions of the Creative Commons Attribution license (http://creativecommons.org/licenses/by/4.0/) 